\title{
Coaches and the Law: A Study of the Training of Coaches in the United States
}

\section{Travis Justin Matthews Sr}

Texas A\&M University Commerce

\section{Lee Waller}

\author{
American University of Ras Al Khaimah; Lee.Waller@auark.ac.ae
}

\author{
Doi:10.5901/mjss.2016.v7n1p475
}

\begin{abstract}
This study examined the necessity for additional coursework and/or professional development to equip coaches to oversee athletic programs within the purview of complicated regulatory laws and regulations. The research was compiled based upon a case study of a large East Texas high school. Findings indicate that coaches are not as cognizant of sports laws and regulations as they suppose. Implications for policy and practice are identified.
\end{abstract}

\section{Introduction}

Coaching is a difficult and stressful occupation. The attributes that prepare a good teacher and the attributes that prepare a good coach are not always the same. Successful coaching requires a unique skill set. Coaches must be prepared to interact with community leaders, school administrators, compliance agencies, parents, fellow teachers, students, and other coaches. Favorable interaction does not guarantee success in the sport. Many beginning coaches are not adequately prepared to deal with complex legal and governance issues associated with successful coaching. Athletics related litigation is not a recent phenomenon.

\section{Review of the Literature}

Appenzeller (1975) indicates that "litigation has become ... a vital factor in the life of the athlete and coach." Likewise, Baley and Matthews (1988) assert that "the number of these lawsuits has continued to rise to the point where the continuation of school athletic programs is being threatened."

Most coaches desire greater cognizance of the laws governing their athletic programs and fields. Constraints on time and demands related to teaching often interfere with participation in on-going professional development. Baley and Matthews (1988) suggest that while there are several areas that cannot be changed by coaches the "acquisition of knowledge and understanding of safe procedures in physical activities and their behavior ... are entirely in their control."

Schutten and McFarland (2005) emphasize the responsibility of educators to focus professional development activities in the areas of greatest challenge. No educator can master everything. Educators must evaluate the emerging difficulties associated with their professions and take positive action to master rising issues. Coaching certainly falls under this directive. Coaches must recognize the problems associated with increased athletic related litigation and take positive action to acquire the skill sets essential for success. At least one major portion of professional development for coaches should focus on increasing ethical and regulatory compliance. Compliance requires knowledge of and adherence to regulatory expectations. Coaches must know and obey the rules and regulations associated with their sport.

The rise in athletic related litigation may stem from the many and diverse expectations that are placed on coaches. In addition to the rigorous requirements associated with traditional instruction, coaches are expected to master their sports, challenge and motive players, and interact with the community while they oversee legal and regulatory compliance. All of these expectations generate extra work while providing minimal additional pay. Accordingly, motivation to adjust to a rapidly changing legal environment may suffer.

The experience of a coach may have a tremendous effect on understanding of these regulatory expectations. While experience does not always translate into knowledge, more experienced coaches are likely to have encountered compliance issues and subsequently comprehend the repercussions of non-compliance. Additionally, coaches with collegiate or professional experience may possess greater understanding of current rules and regulations. Gender issues 
may also arise in some sports as female coaches may be newer to the field, fewer in numbers, and face acceptance issues relating to longevity of service.

The rapidly changing coaching profession requires the acquisition of innovative and heightened skill sets. Coaches must devote themselves to understanding new and emerging interpretations of the laws and regulations governing their fields. In fact, mastery of the most current legal interpretations impact more than their personal livelihood and success. School districts, athletes, and the community can be negatively impacted by failure to comply with regulatory expectations.

The Texas High School Coaches' Association (THSCA) represents a major portion of coaches in Texas. THSCA (2005) formulated a Code of Ethics (COE) that underlies the values that should be held by coaches in the Lone Star State. The COE emphasizes that a person choosing the coaching profession, "... assumes an obligation to conduct himself in accordance with its ideals." The COE additionally states that the coaching profession is dependent upon the manner in which Texas coaches. "... live up to both the letter and the spirit which the code represents" (p. 18). The responsibility of upholding the ideals of the profession clearly rests upon the shoulders of individual coaches. Sportsmanship, integrity, and compliance must not only be practiced, but these attributes must be instilled in participating athletes. The THSCA establishes the expectation that coaches exert tremendous influence for good or bad. Coaches must lead by example and practice, "... winning without boasting and losing without bitterness" (p. 19).

THSCA requires that coaches be thoroughly acquainted with the rules of the game. Current official rule-books relating to the specified sport should be studied and reviewed. Coaches are expected to appropriate time to acquire and disseminate an understanding of the rules and regulations to player athletes and other relevant individuals such as school district administrators and personnel. THSCA expects coaches to demonstrate respect and adherence to all rules and regulations appropriate to the sport. Intentional exploitation of gaps within the rules is prohibited (p. 20).

While the THSCA has adopted ideals directly related to coaching, the University Interscholastic League (UIL) has classified violations and established procedures and safeguards to foster a system of equity within Texas academic and athletic competition. Chapter 1.F.51 of the UIL Constitution and Contest Rules establishes differing levels of violations. These range from outright and intentional violation of the UIL standards to more minor oversight issues (UIL, 2006). Negligence in regard to these expectations is a major factor leading to litigation. Cunningham (2001) proposes that established negligence and size of awards in cases of litigation are directly related. This study further states the importance of knowledge and adherence to the rules and regulations in limiting school and personal liability. Additionally, Cunningham points out that, "... if a coach is aware of the duties for which he or she is responsible and has professional training to fulfill those responsibilities, then that coach will have less chance of being sued" (p. 14).

Nadeau (1995) indicates that the relationship between the legal rights of the student athlete and the legal responsibility of coaches has become increasingly defined with each new case of sports litigation. Coaches have an established duty of care to ensure the safety of athletes (p. 29). Courts have also imposed a standard of care in regard to safety rules and regulations which have been established for a particular sports activity; the age and competence level of the participants; and the actions or lack of action by coaches (p. 34). This implied legal responsibility further highlights the need for adequate and extensive professional development to prepare and support coaches as they practice their chosen profession.

\section{Purpose of the Study}

This study examined the necessity for additional coursework and/or professional development to equip coaches to oversee athletic programs within the purview of complicated regulatory laws and regulations. This study uniquely highlights the accuracy of perceptions held by coaches in regard to their understanding of legal issues and liabilities relating to their chosen sport. The study also examines the adequacy of existing professional development activities in equipping coaches to navigate the complex environment of regulatory expectations. Failure to deliberate these important issues may expose coaches and their respective school districts to serious and damaging litigation. Adequate professional development may serve to aid in compliance with regulatory agencies.

\section{Research Methodology}

A large East Texas school district was chosen to solicit responses from identified participants due to the availability of a larger sample size, more diversity in regards to both gender and ethnicity, and a greater range of age. The geographic location was a result of proximity to the researcher, and the ease of obtaining information. The sample obtained may be classified as a convenience sample. Waller and Lumadue (2013) indicate that convenience samples may provide 
meaningful findings to guide research and practice.

An online survey instrument was created by the researcher. The survey instrument consisted of several ordinal ranking scale questions. The survey was an online survey, which was e-mailed to the coaches. The survey was designed so that the coaches had to respond to interpretive and ethical considerations specific to UIL rules and regulations. These questions were designed to simultaneously examine the consistency of perceptions and practice (Lumadue \& Waller, 2013). SPSS was used to provide descriptive information and to examine Pearson product-moment correlations.

Correlational analysis is deemed appropriate for establishing relationships between variables of interest. Pearson correlations having absolute values more than 0.70 were deemed to be highly significant. Correlations having absolute values between 0.50 and 0.69 were deemed to be moderate. Correlations having absolute values between 0.30 and 0.49 were deemed weak (Waller \& Lumadue, 2013).

\subsection{Research Questions}

The following two research questions guided this study.

1. What are the perceptions of coaches regarding their understanding of the rules and regulations appropriate to their respective sports?

2. Do coaches indicate the need for additional professional development in order to clarify their understanding of the rules and regulations appropriate to their respective sports?

These questions were answered based on interpretation of the values of the Pearson $r$ coefficients.

\subsection{Research Hypotheses}

The following research hypotheses were utilized in support of Research Question 2.

Ho: No relationships exist between or among the responses of coaches regarding their understanding of the rules and regulations appropriate to their respective sports.

Ha: Relationships exist between or among the responses of coaches regarding their understanding of the rules and regulations appropriate to their respective sports.

\subsection{Delimitations and Limitations}

The study was delimited to one large East Texas high school. As with any survey utilizing self-reporting, the study is limited by the accuracy and truthfulness of the responses.

\section{Research Findings}

Seventeen participants completed this survey.

\subsection{Research Question 1}

The survey reflected several different attributes. The age groups ranged from 18-25, 26-30, 31-35, 36-40, 41-45, 46-50, $51-55,56-60$, and $60+$. The percentages that correspond with those age groups were $11.8 \%, 17.6 \%, 5.9 \%, 11.8 \%, 5.9 \%$, $17.6 \%, 11.8 \%, 11.8 \%$, and $5.9 \%$ respectively. The average coaching experience was taken from one to thirty plus years coaching. This was then used to determine those new to coaching (less than 10 years experience) and experienced coaches (those with more than 10 years experience). Thirty five percent of the sample was considered new and sixty five percent experienced. The sample also showed $58.8 \%$ with only a bachelor's degree and $41.2 \%$ with a master's degree. The sample was predominately male $71 \%$, versus $29 \%$ female. The remaining questions were designed to elicit information for four types of questions. They were issues pertaining to rules, ethics, professional development, and job satisfaction.

The first rules question asked, "I would speak out against school board policy that did not allocate adequate resources to athletic programs" (Matthews, 2006). This question split respondents down the middle with an arithmetic mean of 3.06 . As a determination based on this question $71 \%$ of those surveyed were not properly trained that they have the right to speak against policy relating to their specific discipline, which in this case was athletics. 


\subsection{Research Question 2}

Review of the Pearson $r$ coefficients indicated several values in the moderate to strong relationship range. Accordingly, the null hypothesis, Ho, was rejected in favor of the alternate hypothesis, Ha. Relationships were found to exist between or among the responses of coaches regarding their understanding of the rules and regulations appropriate to their respective sports.

The Pearson's r coefficient as related to new coaches was .412, compared with .072 for experienced coaches based on gender as the dependent variable. This showed a stronger relationship between gender and this rule for coaches that were less experienced. Similarly, if looking at the Pearson's $r$ for cases involving level of education and this rule, there was little evidence that level of education and this rule had much of a relationship regardless of the experience of the coach, .307 for new coaches and .274 for experienced. The Pearson's $r$ with the dependent variable age evidenced a stronger relationship between new coaches .054 than for experienced coaches .076. This demonstrated that education rather than age or gender in this case had a closer relationship to the level of experience the coach had for this rule. This evidenced that experience and this rule are not related, so the perceptions must be an issue of knowledge of the rule. While other questions on rules were straight forward, one showed coaches either not aware of rules or in direct violation of these rules. The case involved whether "I have given over-the-counter medication to athletes" (Matthews, 2006). Of those surveyed, 53\% had given athletes over-the-counter medications.

Likewise, in the analysis of the Pearson's $r$ as related to new coaches was .156, compared with .696 for experienced coaches based on gender as the dependent variable. This showed a stronger relationship between gender and this rule, for coaches that were more experienced. Similarly, if looking at the analysis the Pearson's $r$ for cases involving level of education and this rule, there was little evidence that level of education and this rule had much relationship regardless of the experience of the coach, .07 for new coaches and .02 for experienced. The Pearson's $r$ with the dependent variable age showed that there was a stronger relationship between new coaches at .582 than for experienced coaches at .387. This shows that gender rather than age or education in this case had a close relationship to the level of experience the coach had for this rule. This also indicated that gender and experience had a direct reflection in determining who would violate this rule.

A serious problem occurred with the issue of professional development. Most participants (69\%) were likely or very likely to attend bi-yearly training on rules and laws. They were also likely and very likely to read the UIL Constitution (59\%), and read the rulebook (65\%). A slim majority believed that others know the rules better than they do (53\%), and a slim majority (53\%) would take professional development seriously. It seemed while the participants realized there was a need to receive training, and they were likely to attend, but they would not take the training seriously.

Analysis of the data shows that the participants on the surface could be classified as very ethical. Under the surface shows differing ideas on how ethical the respondents were. For the purpose of reporting oneself, $88 \%$ would report themselves for violation of rules. Yet in comparison to rules based questions 53\% would give over-the-counter medication to athletes. This was a violation that they themselves must be unaware of; otherwise there would be a lower percentage of coaches that gave over-the-counter medication to athletes. The participants would equally report coaches on staff with those from another school (82\%). Also disconcerting was that $53 \%$ would violate a rule if they saw others in violation of the rule. Top this with $56 \%$ have knowing or unknowingly violated a rule/law, it showed that while they believe themselves to be ethical, they were in fact not.

\section{Conclusions and Recommendations}

This study, while not large enough in scale, did give a snapshot of what the expected answers would be. It would show that most coaches believe that they were well prepared and ethical when it comes to rules and sports related laws. The actuality was that while they were unethical, it was largely because they lacked the adequate training to know that they were breaking the law. This study also pointed out that while training was necessary, it was not always the solution if it was not going to be run correctly, or taken seriously by the coaches. Further questioning would be helpful to determine further levels of ethical violations, or issues that involve rules.

If this problem exists for all school districts, then the recommendation would be to find a better way to train coaches. This study should be carried out further at both the national and statewide levels to determine if this is need throughout the United States. If the national levels are the same then there could be an issue with the way that coaches are taught. This could lead to institutions of higher learning to create course work to partially eliminate the problem.

This information would then, in turn, be useful for those governing bodies that create rules and laws that govern sports. If it was know that coaches are deficient in a particular area, then they could make language clearer and more 
understandable. They could also create workshops that coaches could use for professional development purposes. This is limitedly done with coaches meetings before the beginning of a season with the officials. It needs to be expanded more to include the general rules that govern all sports, not just the individual.

Further study would need to consider the ethical impact that coaches have in their decision-making processes. While it is believed that education will help eliminate a majority of the violations; are those that occur afterwards an ethical decision by the coach to purposely break the rules/laws? Is this ethical decision conscious or subconscious? While this would create numerous problems for researchers, it would show that through education and ethics coaches could be able to eliminate the majority of rule and law violations.

The result is coaches and districts that are either confused or not aware they need to know all the information. When this is compounded with lack of funding, it creates a huge predicament. The troublesome vacuum left shows that there is a need for coaches and districts to have continued professional development with regards to sports rules and laws. While education is needed to alleviate the problem, it is not the complete solution. Further emphasis should also be placed on coaches to teach the sports rules and laws to their players and assistant coaches.

This is very similar to what has gone on with the general education and special education laws. School district under the pressure of being sued for improper applications of laws faced the pressure of being sued. It was because of this pressure that districts began implementing training and changes to prevent themselves from being sued.

Additionally, colleges offer coursework, some implemented into all coursework that train future teachers and administrators in educational law. The question of whether this additional training has affected outcomes has not been focused on greatly, yet the assumption is that it has eliminated violations by teachers and districts.

\section{References}

Appenzeller, H. (1975). Athletics and the law. Charlottesville, VA: The Michie Company.

Baley, J. A., \& Matthews, D. L. (1988). Law and liability in athletics, physical education, and recreation. Dubuque, IA: WM. C. Brown Publishing.

Cunningham, R. J. (2001). Perceptions of coaches in small colleges regarding sport law and sport injury. Dissertation Abstracts International, 62 (04), 1359A. (UMI No. 3013159)

Lumadue, R. \& Waller, L. (2013). Educational Research Today. (1st ed.). Cupertino, CA: Apple iTunes Connect. Retrieved from https://itunes.apple.com/us/book/educational-research-today/id691632696?mt=11

Nadeau, S. R. (1995). The legal aspects of the rights of student-athletes, coaches, and administrators at the collegiate level. Dissertation Abstracts International, 56 (09), 3502A. (UMI No. 9600774)

Schutten, M. \&, McFarland, A. J. (2005). Comparative advantage: An economics lesson in collaboration for teachers and coaches. Physical Educator, 62 (2), 58-65.

Texas High School Coaches' Association. (2005, October). Code of ethics. Texas Coach, 18-21.

University Interscholastic League. (2006). 2005-2006 Constitution and contest rules. Retrieved February 9, 2006, from http://www.uil.utexas.edu/policy/constitution/index.html.

Waller, L., \& Lumadue, R. (2013). Correlational Analysis. (1st ed.). Cupertino, CA: Apple iTunes Connect. Retrieved from https://itunes.apple.com/us/book/correlational-analysis/id656763624?ls=1 